\title{
A Study of Maintenance Stopping Times: A Case Study in a Food Industry
}

\author{
Vlamir F. Barriento, Jorge A. Achcar, José Luis G. Hermosilla, Ethel C. Chiari da Silva \\ Engineering Graduate Program, University of Araraquara, Araraquara, S.P., Brazil
}

\begin{abstract}
In food production industries, it is needed every day, a better understanding of industrial results to find new profit opportunities to become more competitive in the market. This work presents an equipment maintenance study in a food industry located in São Paulo province, Brazil using different statistical techniques. Several factors that make up the characteristics of the context in which each maintenance worker is in, are considered in this study as they may affect the response of employees related to better results. Several factors can affect the performance of the industrial equipment and maintenance professionals as service workshop, main characteristic of service, type of service, year, work shift, function and area of service among many others. Under a statistical approach to analyze equipment maintenance times a data set is analyzed under different statistical modeling approaches in order to identify which factors can impact on the performance of the maintenance area.
\end{abstract}

Keywords: Maintenance, Availability, Time Machine Stopping, Performance, Food Industry.

\section{INTRODUCTION}

Industries in all sectors understand that it is a critical need to have adequate maintenance in their facilities [9]. The maintenance process adds value to the process in terms of profit, quality, time and service [15]. Without high-quality maintenance, an industry may be at a major disadvantage in the marketplace that increasingly demands low-cost, high quality products to be delivered in a short time [1]. In general, scheduling and performing maintenance is part of the business planning of any industry, emphasizing operating revenue, profits and other financial results. Many industrial maintenance studies consider several indicators to evaluate the quality of maintenance processes. In practice, these indicators measure efficiency, efficacy, effectiveness, productivity and quality of maintenance actions $[2,3,6]$.

In this study developed in the maintenance sector of a large food industry, the main goal is related to the search of appropriate statistical models to be fitted by the maintenance data set and to find important factors that lead to larger (or shorter) maintenance (repair) times for the food industry. Among these statistical models, we have used analysis of variance (ANOVA) models, linear regression models with normal errors and reliability Weibull regression models introduced in the literature. The present work was developed in the maintenance area of a large food industry, located in São Paulo province, southeast of Brazil, with data collected through 42,071 records of specific indirect documentation (machine, downtime, employee, time, shift, type of service and year) of the company studied between the years of 2012 to 2015. In summary, we have the following goals:

- To identify statistical models to the maintenance (repair) times of the food equipment industry to get a statistical analysis of the non-scheduled downtime for maintenance of machinery and equipment.

- To verify if some covariates related to each maintenance operator (service workshop, main characteristic of service, type of service, year, work shift, function and area of service) affect maintenance (repair) performance times. 
Vlamir F. Barriento et al. "A Study of Maintenance Stopping Times: A Case Study in a Food Industry"

\section{USE OF RELIABILITY MODELS}

Several studies have used simulation methods and other statistical techniques usually considering transformed data to optimize maintenance problems under an analytical and mathematical approach. Another possibility in the analysis of maintenance data would be to consider maintenance times on the original scale. In this way, concepts of industrial reliability models are introduced in this section.

\section{Reliability Function}

Reliability can be defined as the probability of a component or system operating over a given period of time $t$ when used under certain operating conditions [5]. A random variable $\mathrm{T}$, usually continuous, which represents the failure time, is specified by its reliability or survival function $R(t)$ or by the failure rate function [10]. The reliability function also called the survival function is given by,

$R(t)=P(T>t)$

\section{Risk Rate Function or Failure Rate}

The risk rate function or failure rate denoted by $\mathrm{h}(\mathrm{t})$, is the probability of failure occurring in a time interval $\left[t_{1}, t_{2}\right]$, since it did not occur until time $t_{1}$, in other words, it represents the proportions of failures occurring per unit of time. The probability of failures in the interval $\left[t_{1}, t_{2}\right]$, can be expressed in terms of the reliability function as $R\left(t_{1}\right)-R\left(t_{2}\right)$. Thus, the failure rate in the interval $\left[t_{1}, t_{2}\right]$ is expressed by $\left[R\left(t_{1}\right)-R\left(t_{2}\right)\right] /\left[\left(t_{2}-t_{1}\right) R\left(t_{1}\right)\right]$. In general, one can represent the interval $\left[t_{1}, t_{2}\right]$ by $(t, t+\Delta t)$, that is, $t_{2}$ $=\mathrm{t}+\Delta \mathrm{t}$ and, $\mathrm{h}(\mathrm{t})=[\mathrm{R}(\mathrm{t})-\mathrm{R}(\mathrm{t}+\Delta \mathrm{t})] /[\Delta \mathrm{t} \mathrm{R}(\mathrm{t})]$.

Assuming a rather small $\Delta \mathrm{t}, \mathrm{h}(\mathrm{t})$ represents the instantaneous failure rate, or risk rate, at time $\mathrm{t}$ conditional to survival to time $t$, that is, it describes how the instantaneous failure rate changes with time [8]. Thus, one can find a very useful formula for the risk function $h(t)$ given by $h(t)=f(t) / R(t)$ where $\lim \{[\mathrm{R}(\mathrm{t})-\mathrm{R}(\mathrm{t}+\Delta \mathrm{t})] / \Delta \mathrm{t}\}=\mathrm{f}(\mathrm{t})$ when $\Delta \mathrm{t} \rightarrow 0$ and $\mathrm{f}(\mathrm{t})$ is the probability density function of the random variable $\mathrm{T}$.

\section{Use of the Weibull Distribution for the Maintenance (Repair) Times}

A very popular probability distribution in the area of industrial reliability is the Weibull distribution with two parameters $[14,7,12]$. Its probability density function is given by,

$f(t)=\left[\alpha t^{\alpha-1} / \lambda^{\alpha}\right] \exp \left\{-(t / \lambda)^{\alpha}\right\}$

where $t_{i}>0$ denotes the machine downtimes. The parameters $\lambda$ and $\alpha$ respectively denote scale and shape parameters. Different values of $\alpha$ lead to different forms for the distribution, which makes it very flexible in data analysis for lifetime data. The reliability function and the risk rate function for the Weibull distribution are given, respectively, by,

$\mathrm{R}(\mathrm{t})=\exp \left\{-(\mathrm{t} / \lambda)^{\alpha}\right\}$ and $\mathrm{h}(\mathrm{t})=\alpha \mathrm{t}^{\alpha-1} / \lambda^{\alpha}$

Observe that if $\alpha=1$, it gives an exponential distribution, that is, the exponential distribution is a special case of the Weibull distribution. Therefore the function $\mathrm{h}(\mathrm{t})$ given by (5) is strictly increasing for $\alpha>1$ (that is, the occurrence times of the event of interest are smaller), strictly decreasing for $\alpha<1$ (that is, the occurrence times of the event of interest are longer) and constant for $\alpha=1$. Thus, there is a great flexibility of fit for the data.

Let us assume a Weibull regression model for the repair times defined by,

$\log (\mathrm{t})=\beta_{0}+\beta_{1}$ function $+\beta_{2}$ shift $+\beta_{3}$ area $+\beta_{4}$ typeservice $+\beta_{5}$ characservice $+\beta_{6}$ year $+\beta_{7}$ service workshop $+\sigma \varepsilon$ 
where $t$ are the maintenance times; $\beta_{0}, \beta_{1}, \beta_{2}, \beta_{3}, \beta_{4}, \beta_{5}, \beta_{6}$, and $\beta_{7}$ are the regression parameters. The parameter $\sigma$ is related to the shape parameter of the Weibull distribution (4) by the relation $\sigma=$ $1 / \alpha$. The term $\varepsilon$ in (6) is a random quantity with an extreme value distribution (Nelson, 2004; Lawless, $1982)$ with probability density function given by $\mathrm{f}(\varepsilon)=\exp \{\varepsilon$-exp $(\varepsilon)\}, \infty<\varepsilon<\infty$. Considering the regression model (6), the survival or reliability function [8] at a fixed time $t$ is given by,

$\mathrm{R}(\mathrm{t})=\exp \left\{-\mathrm{t} / \exp \left[\beta_{0}+\beta_{1}\right.\right.$ function $+\beta_{2}$ shift $+\beta_{3}$ area $+\beta_{4}$ typeservice $+\beta_{5}$ characservice $+\beta_{6}$ year + $\beta_{7}$ service workshop $\left.]^{\alpha}\right\}$

\section{MAINTENANCE DATA ANALYSIS AND DATA SET}

The studied food industry is located in the state of São Paulo, Brazil, and operates in the segment of biscuits, toasts and snacks. A statistical analysis of data related to the times to failure or occurrence of some event of interest such as maintenance time may lead to better strategies for maintenance of different types of equipment and possible discoveries of factors that lead to better performance in equipment maintenance. Some of these possible factors that can affect maintenance times are the industry sector, type of equipment, equipment models, work shifts, cause of failure or maintenance workshop. The main goal of this study is related to the study of the maintenance times of industrial equipment, an area linked to the theory of industrial reliability. For this purpose it will be analyzed a data set denoting the downtimes for maintenance (repair) due to equipment failures in a large industry in the food sector.

Associated with these observations, we have some factors that can affect maintenance times of the equipment function, area, service type, main feature of service and year. These possible factors affecting the repair times and their levels are codified in the following categorical variables:

- Function: (1) Auxiliary of mechanical maintenance packing machines; (2) Mechanical maintenance technicians packaging machinery; (5) General mechanical maintenance assistant; (6) General mechanical maintenance technicians; (7) Electro-Electronic maintenance technicians; (9) Electrical and electronic maintenance assistant; (13) other.

- Work Shift: (1) First shift (6:00 a.m. to 14:45 p.m); (2) Second shift (14:45 p.m. to 22:50 p.m.); (3) Third shift (22:50 p.m. to 6:00 a.m.); (4) Shift room (10:00 a.m. to 7:00 p.m.); (5) Administrative (8:00 a.m. to 6:00 p.m.).

- Area: (1) Production line 1; (2) Production line 2; (3) Production line 3; (4) Production line 4; (5) Production line 5; (6) Production line 6; (7) Production line 7; (8) Production line 8; (9) Production line 9; (10) Production line 10; (11) Production line 11; (12) Production line 12; (13) Production line 13; (14) Production line 14; (15) Production line 15; (16) Production line 16; (17) Production line 17; (23) Reservation field; (25) Lighting; (26) External silos; (27) Cooling tower; (28) Water treatment; (29) Shipping; (30) Central air compressor; (31) Steam power station; (32) Gas plant; (33) Generator set-up; (34) Pump house; (35) Tanks area; (36) Secondary cabin; (37) Warehouse; (38) Central packing; (39) Manufacture 1; (40) Manufacture 2; (41) Nobreaks room; (42) Creams room; (43) Fat plasticizer; (44) Office; (45) Offices; (46) Engineering; (47) Common industrial areas.

- Type of Service: (1) Corrective maintenance; (2) Scheduled services (preventive and scheduled corrective); (3) Inspections; (4) Lubrication.

- Main Service Feature: (1) Adjust; (2) Follow up operation; (3) Align; (4) Adapt; (6) Power blockage; (7) Auxiliary; (8) Inspections; (9) Reservation field; (10) Repair; (11) Making; (12) Lubricant; (13) Reservation field; (14) Remove leakage; (15) Reset; (16) Replace 1; (17) Replace 2; (18) Remove; (19) Review; (20) Clear / Organize; (21) Set Up; (22) Unlocking; (23) Identify; (24) Fastening; (25) Landing electrically; (26) Install; (27) Inverter; (28) Improvement; (29) Test.

- Service Workshop: (1) Electro-electronics; (2) Mechanics of packaging machinery; (3) General mechanical engineering.

- Years: 2012, 2013, 2014 and 2015. 
Vlamir F. Barriento et al. "A Study of Maintenance Stopping Times: A Case Study in a Food Industry"

\section{DATA ANALYSIS}

In Figure 1, it is presented the histograms of the original and transformed maintenance times (log scale). A better symmetry is observed for the transformed data (approximate normality).

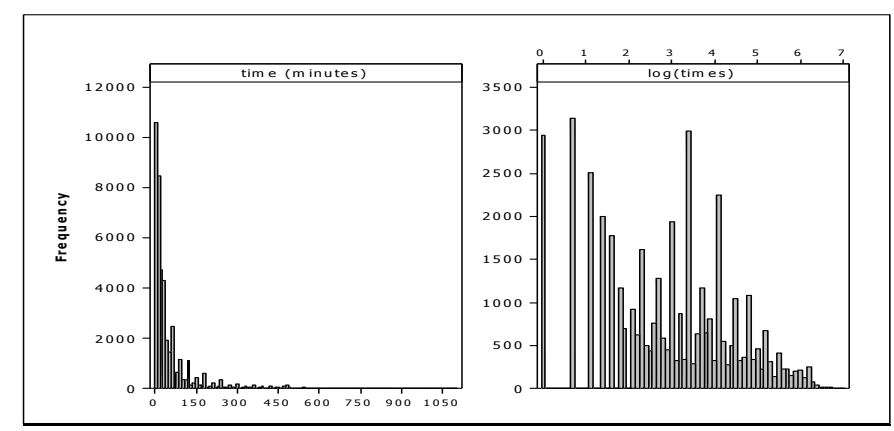

Figure1. Histograms for original and transformed maintenance times (log scale)

\section{Use of ANOVA (Analysis of Variance)}

In this section we have used a ANOVA model [11] with one classification for the logarithms of the maintenance times. The analysis of variance was applied for the data considering the transformed count data to a logarithmic scale [log(times)] to verify some standard assumptions needed for ANOVA as normality of the residuals and constant variance. With this transformation, this analysis can be very useful in checking the differences between the means for each level and for each factor. From the results in Table 1 (use of Minitab ${ }^{\circledR}$ software), it is possible to conclude that for all factors there are significative differences among the levels of each factor ( $\mathrm{p}$-value $<0.001$ for all cases).

\section{Use of Multiple Regression analysis for the Transformed Data}

In this section, a multiple regression analysis for the dataset is introduced in order to study the joint relationship between the response variable (maintenance or repair times) with some covariates, such as service workshop, main characteristic of service, type of service, year, work shift, function and area of service. A multiple linear regression with normal errors is assumed considering the response maintenance times also transformed to a logarithmic scale.

Table1 Results of ANOVA.

\begin{tabular}{|l|l|l|l|l|l|}
\hline Factors & \multicolumn{1}{|c|}{ DF } & \multicolumn{1}{c|}{ SS } & \multicolumn{1}{c|}{ MS } & \multicolumn{1}{c|}{ F } & \multicolumn{1}{c|}{ P } \\
\hline Function & 6 & 11668.5 & 1944.8 & 879.34 & $<0.001$ \\
Error & 42064 & 93029.2 & 2.2 & & \\
Total & 42070 & 104697.8 & & & \\
\hline Shift & 4 & 8242,4 & 20060.6 & 898.67 & \\
Error & 42066 & 96455.4 & 2.3 & & \\
Total & 42070 & 104697.8 & & & \\
\hline Area & 38 & 8879.5 & 233.7 & 102.50 & $<001$ \\
Error & 42032 & 95818.2 & 2.3 & & \\
Total & 42070 & 104697.8 & & & \\
\hline Type service & 3 & 51505.0 & 17168.3 & 13577.40 & \\
Error & 42067 & 53192.8 & 1.3 & & \\
Total & 42070 & 104697.8 & & & \\
\hline Main service & 26 & 56104.4 & 2157.9 & 1867.03 & \\
Error & 42044 & 48593.4 & 1.2 & & \\
Total & 42070 & 104697.8 & & & \\
\hline Year & 3 & 1116.7 & 372.2 & 151.18 & \\
Error & 42067 & 103581.0 & 2.5 & & $<001$ \\
Total & 42070 & 104697.8 & & & \\
\hline Serv workshop & 2 & 9971.0 & 4985.5 & 2214.05 & \\
Error & 42068 & 94726.8 & 2.3 & & \\
Total & 42070 & 104697.8 & & & \\
\hline
\end{tabular}

(DF: degrees of freedom, SS: sums of squares, MS: mean squares, F: Snedecor F distribution; P: $p$-value) 
In the statistical analysis, when the main objective is to verify the combined effect of the covariates on a response denoted by $\mathrm{Y}$, multiple linear regression techniques are usually employed $[4,13,11]$. In this way, although most covariates are non-ordinal, a multiple linear regression model is assumed that can be useful for predictions considering the covariates (independent variables) function $\left(\mathrm{x}_{1}\right)$, shift $\left(\mathrm{x}_{2}\right)$, area $\left(\mathrm{x}_{3}\right)$, service type $\left(\mathrm{x}_{4}\right)$, main service characteristic $\left(\mathrm{x}_{5}\right)$, year $\left(\mathrm{x}_{6}\right)$, service workshop $\left(\mathrm{x}_{7}\right)$ and transformed log response (maintenance time) to satisfy some assumptions required for the use of regression models, given by :

$Y_{i}=\beta_{0}+\beta_{1} X_{1 i}+\beta_{2} X_{2 i}+\beta_{3} X_{3 i}+\beta_{4} X_{4 i}+\beta_{5} X_{5 i}+\beta_{6} X_{6 i}+\beta_{7} X_{7 i}+\epsilon_{i}$

$\varepsilon_{\mathrm{i}}$ are random errors assumed to be independent, with a normal distribution with zero mean and constant variance $\sigma^{2}, i=1,2, \ldots, n$.

The least squares estimators (LSE) of the coefficients of the regression model (1) are obtained using the Minitab ${ }^{\circledR}$ software, version 16 , from where we get the following fitted model:

$\log ($ time $)=33,3-0,112$ (Function) $+0,118($ Shift $)+0,0163$ (Area) $-0,826$ (Type service) $+0,0843$

(Characteristic service) - 0,0146 (Year) + 0,0573(Service workshop)

From the results obtained from the software Minitab ${ }^{\circledR}$, version 16 given in Table 2 (least squares estimators and p-values to test whether the regression parameters are equal to zero) obtained for this model, it is observed that all factors except year are significant considering a fixed significance level equals to 0.01 ( $\mathrm{p}$-value $<0.01$ for all covariates) affecting the response time of maintenance. This proves the results obtained previously by the other statistical analysis (ANOVA). Assuming a fixed significance level equals to 0.05 , we observe that all covariates have significative effects on the response (p-value $<0.05$ ). The assumption of normality of residuals was verified from residual graphs. We also observed approximately constant variance for the error. In addition, the regression model can be very useful for predictions

In Table 2, LSE is least squares estimate; SD is standard deviation of the coefficient estimator; $\mathrm{T}$ is the Student statistics; $\mathrm{P}$ is the $\mathrm{p}$-value).

Table2. Least square estimates, Student's $t$ statistics and p-value

\begin{tabular}{|c|c|c|c|c|}
\hline Predictor & LSE & SD & T & P \\
\hline Constant & 33.2 & 14.19 & 2.34 & 0.019 \\
Function & -0.11196 & 0.00295 & -37.93 & 24.55 \\
Shift & 0.11811 & 0.00481 & 30.82 & $<0.001$ \\
Area & 0.016288 & 0.000529 & -110.76 & $<0.001$ \\
Type service & -0.82599 & 0.007457 & 83.56 & $<0.001$ \\
Charac service & 0.084266 & 0.001008 & -2.08 & $<0.001$ \\
Year & -0.014644 & 0.007046 & 7.24 & 0.038 \\
Service workshop & 0.057256 & 0.007911 & 0.001 \\
\hline
\end{tabular}

\section{RESULTS ASSUMING A WEIBULL REGRESSION MODEL}

Assuming the Weibull regression model (6) for the maintenance times, Table 3 shows the maximum likelihood estimators (MLE) for the parameters of the Weibull regression model (use of the software Minitab ${ }^{\circledR}$, version 16).

From the results obtained in Table 3, it can be observed that all factors except year are significant (pvalue $<0.05)$ affecting the response time of maintenance. This proves the results obtained previously by the other statistical analysis. As the model captures the combined effect of all covariates on the response (maintenance time), possibly the covariate years presents some dependence with some of the other covariates, which led to non-significance of the years in the response time maintenance.

From the obtained inference results we could point out some brief interpretations based on the knowledge of the maintenance administrator: in the area of electrical and electronic maintenance, the majority of the actions are of a fast solution with few cases where the diagnostic situations are longer. Situations such as adjustments and resets of systems in some cases can even be done without stopping the machine for a long time, a fact evidenced here in this analysis. For the mechanical and auxiliary 
Vlamir F. Barriento et al. "A Study of Maintenance Stopping Times: A Case Study in a Food Industry"

electrical and electronic functions, similar average times are observed as a function of average complexity for the diagnosis and resolution of problems. It is also observed that for mechanical maintenance auxiliaries and building maintenance electricians, they present larger average times due to the lower technical knowledge of the technicians in machines directly related to production.

Table3. Weibull regression model for the repair times

\begin{tabular}{|c|c|c|c|c|}
\hline Predictor & MLE & SE & Z & P \\
\hline Intercept & -10.9045 & 15.1083 & -0.72 & 0.470 \\
Function & -0.124481 & 0.002685 & -43.36 & $<0.001$ \\
Shift & 0.099721 & 0.004778 & 20.87 & $<0.001$ \\
Area & 0.014733 & 0.000552 & 26.70 & $<0.001$ \\
Type service & -0.713355 & 0.006987 & -102.10 & $<0.001$ \\
Service charact & 0.075538 & 0.001118 & 67.54 & $<0.001$ \\
Year & 0.0074933 & 0.0075031 & 1.00 & 0.318 \\
Service workshop & 0.152089 & 0.0079263 & 19.19 & $<0.001$ \\
shape & 0.791631 & 0.002749 & & \\
\hline
\end{tabular}

Related to the area issue, it is noticed that it falls on support areas, which less stopping for preventive interventions and has a very large impact in a common way in all productive areas. Another important fact to point out is that in some conditions of intervention, it is necessary to wait some time until the equipment is in a safe condition of intervention (cooling, for example) and even a special preparation for intervention, such as the availability of tools and differentiated resources (lifting platforms, scaffolding, moving devices, etc.), making maintenance times invariably long but with few occurrences.

It is also observed in the service characteristic that the times observed do not have a very direct relationship with the maintenance area (adaptation, making, remove, install and improve), which always demand a good preparation of the activity involving the vast majority of times parts, tools and even a service provider to aid in the activity. The only characteristic with a strong relation to maintenance is "overhaul", and this situation is characterized by an unscheduled corrective intervention that must have been transformed into a non-scheduled review possibly detected at the time of intervention.

Determination of the Reliability Functions for the Maintenance Times Assuming a Weibull Distribution in Each Factor

The reliability function (5) for a time $t$ gives the probabilities of maintenance times greater than a given value t. Thus, one can have reliability curves at specified times for each factor of interest. Curves with higher probability values at specified times $t$ indicate the components with the highest probabilities of maintenance times being greater than a fixed value t. These curves (service workshop, year, shift and type of service) are given in Figure 2, where the parameters of the Weibull distribution were estimated by MLE for each level of the assumed factor (use of the software Minitab ${ }^{\circledR}$, version 16).

From the graphs of Figure 2 it is also possible the see the levels of factors that implies in larger repair times (high probabilities at fixed times); from these plots we get similar conclusions as obtained using the other statistical approaches.

As a special case, the factor related to service workshop, it is observed that the "workshop 2 (mechanics of packaging machines)" has the characteristic of acting on the final product, which would be the product in its primary packaging, in the format in which it reaches the final consumer. From this point and unlike other workshops, many machine adjustments and long-term performance monitoring are necessary to ensure good quality of final packages. The analysis shows that this is the workshop that stays most of the time, working alongside the machine and equipment, due to the constant need for monitoring. 

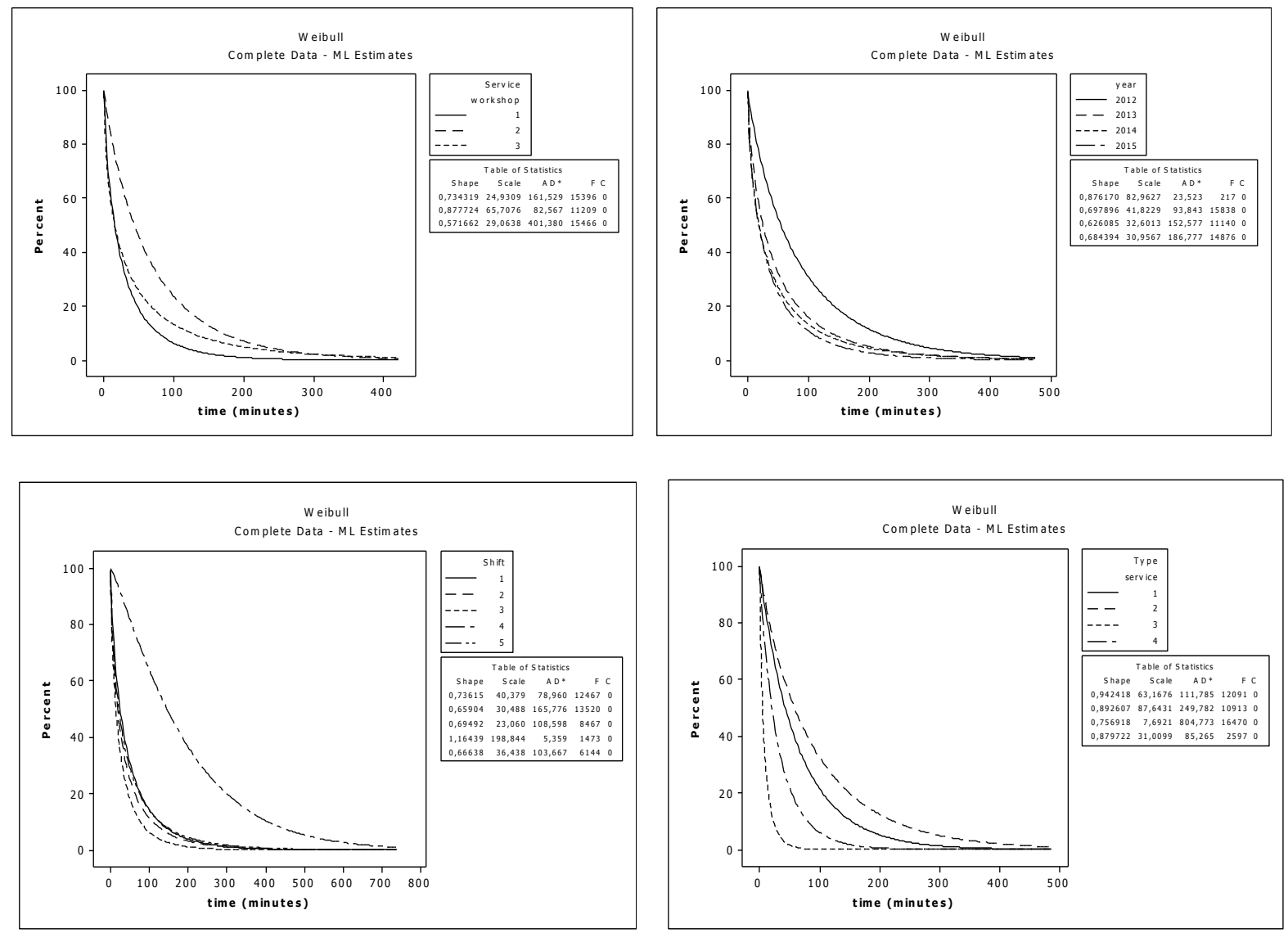

Figure2. Reliability function graphs (Weibull distribution)

Related to the factor shift, an important finding evidenced between shifts is in relation to the average maintenance time in the fourth shift, since most of the activities of this team are related to set-ups, improvements and adaptations of machines and equipment, and such activities usually require more time. In the case of the third shift having a much shorter average time, this is due to the fact that there is less interference in production due to changes in programming and tests, as evidenced by the antagonistic situation of the first and second shifts, which is still supported by the fourth shift in situations emergency, as this differentiated shift (fourth shift) makes the connection between these two schedules.

Related to the factor type of service, the main observation in the type of service is the observation that a quick inspection is being done for a larger programmed intervention, evidencing that a maintenance program is working satisfactorily, if analyzed only under this focus.

Related to the year factor, it is observed that the year 2012 presents greater maintenance times when compared with the years 2013, 2014 and 2015. This result can be characterized as the most important information extracted from this data analysis, which shows with certainty that the strategies traced by the area of maintenance of this company, have been very assertive until now, since over the years, the average times of interventions have been gradually and consistently declining. It should be noted in this analysis that the intervention time of the maintenance area of 2015 is much lower than that analyzed in 2012, which implies with certainly that the maintenance area had a very large contribution in the availability of productive machinery and equipment.

Related to the fator shift, it is observed that shift 4 (10:00 am to 7:00 p.m.) has larger maintenance time when compared to the other shifts, while the other shifts have fairly similar maintenance times.

Related to the factor type of service it is observed that the factor of service type 2 (Scheduled Services - Preventive and Scheduled Corrective) presents a much longer maintenance time when compared to the other types of service. In this way, it is observed that for the studied food industry, most of the 
Vlamir F. Barriento et al. "A Study of Maintenance Stopping Times: A Case Study in a Food Industry"

time of the maintenance activities is related to scheduled services, reaching a much higher average than for the type of service 1 (corrective maintenance) which means that the hours of maintenance man, are applied in a properly way.

\section{CONCLUDING REMARKS}

The statistical analysis of the data obtained for the food industry is of great interest in identifying the causes of the great variability for the maintenance times of different equipment used in the industry. With different models of statistical analysis, it was possible to detect the factors that most affect the variability of the data. It is important to emphasize that the statistical approach undertaken in this article brings benefits to several other productive systems. Some important conclusions:

- The industry must maintain the backbone of the maintenance strategy, as the results showed improvements in results over the years studied.

- Since the professionals of packing machines require a lot of time with adjustments of machines this must be studied with the possibility of some of the activities being transferred to the operation of machines in this area.

- The so-called fourth shift in this study, requires a lot of time with set up and machine preparation. This activity can also be transferred to the operation, resulting in lower operating costs and increased productivity, as the cost of operating labor is lower than that of maintenance.

- The functions of auxiliaries that are the ones with the lowest level of knowledge must be rethought since the results show that they are less efficient in the actions demanding more time in the actions.

- Services such as (adaptation, making, remove, install, improves and reforms) carried out by the maintenance area are helping in the results of the area, which shows that the maintenance area must carry out these types of activities.

\section{REFERENCES}

[1] Cholasuke,C.; Anthony, R.D. The status of maintenance management in UK manufacturing organizations: results from a pilot survey. Journal of Quality in Maintenance Engineering, 10(1), $5-15,2004$

[2] Clifton,R.C. Principles of planned maintenance, Edward Arnold Publishers: London, 1974.

[3] Cokins,G. Activity-base cost management: making it work. Irwin Professional Publishing; Chicago, 1996.

[4] Draper,N.R.; Smith, H. Applied regression analysis. Wiley \& Sons, 1981.

[5] Ebeling,C.E. An introduction to reliability and maintainability engineering. McGraw-Hill Companies. 1997.

[6] Gold, B. Foundations of strategic planning for productivity improvement. Interfaces. Claremond Graduate School, 15(3), 15-30, 1985.

[7] Johnson, N.L.; Kotz, S.; Balakhisnan, N. Continuous univariate distributions, vol 1, Wiley series in probability and mathematical statistics: applied probability and statistics (2nd Ed). Wiley\& Sons, 1994.

[8] Lawless, J.F. Statistical models and methods for lifetime data, wiley series in probability and mathematical statistics, Wiley \& Sons, 1982.

[9] Luxhoj,J.; Thorsteinsson, U.; Riis,J. Trends and perspectives in industrial maintenance management, Journal of Manufacturing Systems, 16(6), 437- 453, 1997. 
Vlamir F. Barriento et al. "A Study of Maintenance Stopping Times: A Case Study in a Food Industry"

[10] Meeker, W.Q.; Escobar, L.A. Statistical methods for reliability data, Wiley \& Sons, 1998.

[11] Montgomery, D.C.; Runger, G.C. Applied statistics and probability for engineers, 5nd Edition, Wiley \& Sons, 2010.

[12] Nelson,W. Applied life data analysis, Wiley -Blackwell, 2004.

[13] Seber, G.A.; Lee, A.J. Linear regression analysis. Hoboken, 2003.

[14] Weibull,W.A statistical distribution function of wide applicability, Journal of Applied Mechanics - ASMC, 18(3), 293- 297, 1951.

[15] Zhu, G.; Gelders, L.; Pintelom, L. Object/objective-oriented maintenance management. Journal of Quality in Maintenance Engineering. 8(4), 306 -318.2002.

\section{AUTHORS' BIOGRAPHY}

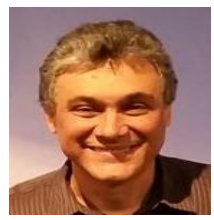

V.F. Barriento, is engineering instructor and coordinator at University of Marilia (UNIMAR). He received a bachelor in Industrial Eletric Engeneering from Santa Cecília University (UNISANTA), Brazil and a MSc in Production Engineering from University of Araraquara (UNIARA), Brazil.

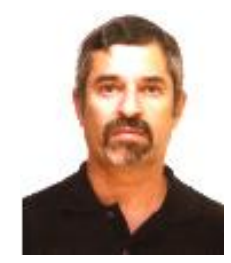

J.A. Achcar, received a bachelor in mathematics from University Paulista (UNESP), Brazil; a master degree in Statistics from University of São Paulo (USP), Brazil and a $\mathrm{PhD}$ in Statistics from the University of Wisconsin, Madison, USA.

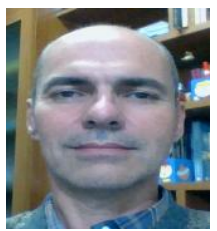

J.L.G. Hermosilla, is Professor at University of Araraquara (UNIARA). He received a bachelor in Mechanical Engineering from University of São Paulo (USP), Brazil; a master degree in Production Engineering from Federal University of Santa Catarina (UFSC), Brazil and a PhD in Mechanical Engineering from University of São Paulo (USP), Brazil.

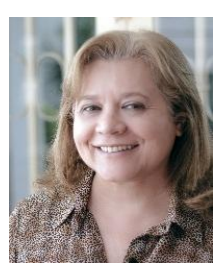

E. C. C. Silva, received a bachelor in Industrial Engineering - Materials - at Federal University of São Carlos (UFSCar), Brazil, in 1990; a master degree (1994) and a PhD (1999) in Mechanical Engineering from University of São Paulo (USP), Brazil. She coordinates the undergraduate program of Industrial Engineering at University of Araraquara (UNIARA), Brazil, and teaches in the Professional Master's Program in Industrial Engineering of the same institution. 